\title{
Plant and Microalgae Derived Peptides Are Advantageously Employed as Bioactive Compounds in Cosmetics
}

\author{
Fabio Apone ${ }^{1,2}$, Ani Barbulova ${ }^{1 *}$ and Maria Gabriella Colucci, ${ }^{1,2}$ \\ ${ }^{1}$ Arterra Bioscience srl, Naples, Italy, ${ }^{2}$ Vitalab srl, Naples, Italy
}

Bioactive peptides (BP) are specific protein fragments that are physiologically important for most living organisms. It is proven that in humans they are involved in a wide range of therapeutic activities as antihypertensive, antioxidant, anti-tumoral, anti-proliferative, hypocholesterolemic, and anti-inflammatory. In plants, BP are involved in the defense response, as well as in the cellular signaling and the development regulation. Most

Edited by:

Jussi Joonas Joensuu,

VTT Technical Research Centre of Finland Ltd., Finland

Reviewed by:

Pedro Carrasco,

University of Valencia, Spain Jules Beekwilder, Wageningen University \& Research, Netherlands

*Correspondence: Ani Barbulova ani@arterrabio.it

Specialty section: This article was submitted to Plant Metabolism and Chemodiversity, a section of the journal

Frontiers in Plant Science

Received: 15 January 2019

Accepted: 24 May 2019

Published: 12 June 2019

Citation:

Apone F, Barbulova A and

Colucci MG (2019) Plant and Microalgae Derived Peptides Are Advantageously Employed as Bioactive Compounds in Cosmetics.

Front. Plant Sci. 10:756. doi: 10.3389/fp/s.2019.00756 of the peptides used as ingredients in health-promoting foods, dietary supplements, pharmaceutical, and cosmeceutical preparations are obtained by chemical synthesis or by partial digestion of animal proteins. This makes them not fully accepted by the consumers because of the risks associated with solvent contamination or the use of animal derived substances. On the other hand, plant and microalgae derived peptides are known to be selective, effective, safe, and well tolerated once consumed, thus they have got a great potential for use in functional foods, drugs, and cosmetic products. In fact, the interest in the plant and microalgae derived BP is rapidly increasing and in this review, we highlight and discuss the current knowledge about their studies and applications in the cosmetic field.

Keywords: bioactive, peptide, plant, microalgae, cosmetics

\section{BIOACTIVE PEPTIDES IN ANIMALS AND PLANTS}

Peptides are short amino acid chains, usually ranging from 2 to 20 units, with a molecular weight under $3 \mathrm{kDa}$. As most of them possess a wide range of biological activities in living organisms, they are generally defined as bioactive peptides (BP). Due to their specific amino acid sequence and 3D conformation, $\mathrm{BP}$ are capable of interacting with a huge number of biological macromolecules and biochemical compounds, modulating several functions and conditions in living organisms (Moller et al., 2008). Their mode of action resembles to that of hormones and drugs, capable of activating signal transduction mechanisms in the cells, leading to an up-regulation or down-regulation of the expression of important regulatory genes. It is proven that in humans endogenous BP are involved in a wide range of therapeutic activities, such as anti-microbial, anti-hypertensive, antioxidant, antitumoral, anti-proliferative, hypocholesterolemic and anti-inflammatory (Sánchez and Vázquez, 2017). Besides their primary functions in triggering transduction mechanisms, they can also exert a 
nutritive function, providing the amino acid units as building blocks for new proteins to cells, thus contributing to the physiological protein turnover (Hartmann and Meisel, 2007).

Analogously, in plants the role of endogenous BP has been extensively studied and linked to defense response mechanisms, as well as cellular signaling during plant development stages (Schaller, 2001). A class of cationic, antimicrobial peptides (AMPs), was found to be involved in the plant innate immune response, which was one of the main mechanisms of defense against pathogens. AMPs exhibited bactericidal and fungicidal activity, thanks to their amphiphilic structure and positive charge, that facilitated the interaction and the integration into the negatively charged microbial membranes (Suarez et al., 2005). Other types of plant endogenous peptides include regulatory $\mathrm{BP}$, such as systemin and enod40, whose roles in the plant wound response, mitotic activity and differentiation have been extensively reviewed (Schaller, 2001).

Signaling peptides, as plant natriuretic peptides (PNP), phytosulfokines (PSK), and rapid alkalinization factor (RAF) were purified from different plant species and it has been established their involvement in homeostatic functions (Salas et al., 2015). Another group of plant signaling peptides, members of the CLE (CLAVATA3/ESPrelated) family, synthesized in the plant apical or root meristem region, were studied for their role in growth and differentiation, as well as in the maintenance of the balance between differentiation and stemness (Ito et al., 2006; Salas et al., 2015).

Nevertheless in both animals and plants many BP exist as free forms, the vast majority of known $\mathrm{BP}$ are produced and released following a chemical hydrolysis or enzymatic intervention, since they are encrypted in the structure of a parent protein. Thus, several classes of proteins from plant and animal origins hide active portions in their structure with specific amino acid sequences, making them potential sources of encrypted BP (Carrasco-Castilla et al., 2012; Bhat et al., 2015). The characterization of the BP released after protein hydrolysis has highlighted their wide range of biological activities related to nutraceutical and medical applications (Maestri et al., 2016). BP-rich hydrolysates, obtained from different legume plants, such as chickpea, soy bean, pea, lentil, mung bean have been studied and characterized for their antimicrobial and antihypertensive activities (Ariza-Ortega et al., 2014; Maestri et al., 2016). Either as purified forms or mixtures, BP have been proposed for the treatment and prevention of various medical conditions due to their cholesterol-lowering effects, antiprotozoal, antiviral, antithrombotic, antioxidant, antihypertensive, and antimicrobial activities (Lemes et al., 2016), and were extensively characterized as nutraceuticals (Moldes et al., 2017) and functional foods (Haque et al., 2008). BP are becoming popular in the skin and hair care field too, as they possess a wide range of biological activities in skin cells and are capable of triggering signal transduction mechanisms, leading to the activation of important gene regulators. Moreover, differently from large proteins, $\mathrm{BP}$ are preferred by formulators thanks to their ability to penetrate into the skin easier and to reach the deeper skin layers whether associated with efficient delivery systems (Badenhorst et al., 2014).

\section{BIOACTIVE PEPTIDES IN THE COSMETIC INDUSTRY}

\section{BP From Synthetic Processes and Animal Protein Digestion}

The BP that are employed in cosmetic applications come from different sources. Two of the most used methods to obtain peptides are the chemical synthesis and the partial digestion of animal proteins. Chemical synthesis involves the use of amino acid mixtures as starting material, allowing to obtain peptides with different amino acid sequence and combinations. The advantage is mostly related to the almost infinite sequences that can be intentionally assembled, giving rise to a huge range of desired functional structures.

One of the examples is the copper complexed-tripeptide GHK, which enhances the synthesis of Extra Cellular Matrix (ECM) proteins in the skin, such as collagen I, thanks to its capacity to penetrate through the stratum corneum and reach the dermis layer (Pickart and Schagen, 2015). A second example is the peptide GEKG, known as tetrapeptide-21, which was studied in vitro and in clinical tests for its capacity to reduce facial wrinkles (Farwick et al., 2011). The tetra-peptide increased collagen production by human fibroblast cultures and induced the expression of type I procollagen mRNA levels in vivo. Histochemical analysis performed on ex vivo skin explants confirmed that GEKG induced the production of procollagen, hyaluronic acid, and fibronectin. The galloyl-RGD, which is a tripeptide conjugated to gallic acid, was differently characterized for its capacity to inhibit free radical formation in $\mathrm{HaCaT}$ keratinocytes at the concentration of $50 \mathrm{ppm}$, and to suppress L-3,4-DihydrOxyPhenylAlanine (L-DOPA) formation and oxidation when used at higher doses (Dae et al., 2014). A Palmitoyl tetrapeptide, which represented a fragment of an immunoglobulin G, was proven to decrease IL-6 secretion in a basal setting, and served as an anti-inflammatory compound after exposure to UVB-irradiation. In vivo reflectance confocal microscopy studies indicated that a blend of the palmitoyl tetrapeptide and another palmitoyl oligopeptide significantly enhanced the synthesis of the ECM factors compared to placebo (Watson et al., 2009). In addition, some neurotransmitter inhibitor peptides, such as the acetyl hexapeptide three which was capable of penetrating the skin and inducing muscle relaxation, has been employed in cosmetic formulas thanks to its effect against wrinkle and fine line formation (Blanes-Mira et al., 2002).

Besides synthetic peptides, other types of peptides commonly used in skin care are those obtained by partial digestion of animal proteins, such as collagen. These peptides, generally defined with the term of matrikins (Aldag et al., 2016), have been extensively studied for their capacity to induce the production of the ECM components in the skin. KTTKS, a peptide derived from the proteolytic hydrolysis of collagen, promoted the production of fibronectin, collagen types I and 
III in skin fibroblasts, through the activation of TGF- $\beta$ pathway (Tsai et al., 2007). A palmitoylated and more stable form of the KTTKS (pal-KTTKS) has been developed and shown to be more effective than its precursor in the collagen induction, thanks for its capacity to better penetrate the skin stratum corneum. The biomimetic tetrapeptide PEGP, due to the presence of the amino acids glycine and proline, was identified as a potent candidate to delay early-onset skin aging by the loss of ECM mass. Once tested, both in vitro and in vivo, it induced collagen I, elastin and fibronectin, resulting into a significant sharpening of the facial contours and wrinkle depth reduction (Maczkiewitz et al., 2018). A further example of BP derived from animal protein digestion is the mixture of peptides obtained from wool keratin. Topical formulations containing keratin-BP $(\mathrm{MW}<1000 \mathrm{Da})$ were described as possessing moisturizing, repair-promoting and potentially radio-protective properties in the skin (Barba et al., 2008).

Instead of topical administration, a BP preparation has been studied for its benefits on the skin, once orally up-taken. The dietary supplementation of a specific bioactive collagen peptide (BCP), derived from porcine type I collagen hydrolysis, significantly reduced the wrinkles volume after 4 and 8 weeks of intake. Additionally, after 8 weeks the content of procollagen type I and elastin was higher by 65 and $18 \%$, respectively, in the BCP-treated volunteers compared to the placebo-treated patients (Proksch et al., 2014).

\section{Disadvantages and Concerns of Synthetic and Animal Derived Peptides}

The described examples of BP for cosmetic use, nevertheless still requested by the market, present certain drawbacks and are not fully accepted by all the consumers, mostly due to the risks associated with the presence of contaminating chemicals used in the process (for chemical synthesis) or the use of animal derived substances (for digested products). The use of chemical reactions to synthesize peptides implies the use of toxic solvents and reagents in the cycle and, although the last step of the process involves the elimination of most chemicals, the final product can still carry contaminating solvent residues or impurities (Guzman et al., 2007; D'Hondt et al., 2014). Even the solid-phase peptide synthesis, the most used manufacturing procedure for drug peptides today, can generate adducts, impurities and unwanted peptide counter ions, such as trifluoroacetate, which can be hardly eliminated from the final peptide product (D'Hondt et al., 2014).

On the other hand, the use of animal proteins in enzymatic digestions implies very strict veterinary controls in the animal source in order to exclude infections from any kind of pathogenic virus, or even the presence of dysfunctional protein aggregates, that can cause very serious diseases in human as well, such as the case of the Bovine Spongiform Encephalopathy (BSE) in cattle. Nevertheless of the several check points during the whole production process, certain risks associated with the presence of animal derived harmful substances cannot be completely abolished (Yokoyama and Mohri, 2008). Besides the safety concern, which certainly represents the most relevant priority for cosmetic brands and consumers, the whole tendency of the market is going toward eco-certified plant derived ingredients. Plant-extracted compounds are becoming always more requested by the market, both because of the trends associated with the idea of well tolerated and less allergenic ingredients, and because strict vegan consumers are progressively increasing among the global world population. For Muslims, for example, additional rules for Cosmetics imply further considerations relative to the religion, which restrict or prohibit any contact with products that are inconsistent with Islam laws. In relation, Halal certification is required for many cosmetic ingredients to attest the product conformity during its whole production cycle with the special attention to the animal origin and the processing (Rigano, 2017). Both the concerns and the preferences toward plant derived material has prompted skin care ingredient producers to substantially invest on alternative ways to obtain BP, which can be analogously effective in terms of biological activity as their animal-derived or synthetic counterparts, and fully guaranteed for safety and sustainability.

\section{Plant and Microalgae-Derived Peptides for Cosmetic Applications}

All plant and microalgae-derived peptides used in Cosmetics today, in particular in the skin care market, are formulated as mixtures of many different protein fragments, obtained from hydrolysis of bigger proteins, using either the chemical or enzymatic methods (Table 1). By choosing a specific protein source, and by modulating the extent and the conditions of the hydrolytic process, it was possible to obtain BP of different nature, length and composition, adapted to fulfill desired biological functions. All the examples that we have reported and discussed hereafter refer to raw peptide preparations, often containing other plant cell metabolites, whose activity has been characterized, either in vitro or in vivo, for their capacity to activate significant biological functions in skin cells, acquiring promising potentialities to be developed as cosmetic active ingredients.

An Avena sativa (oat) peptide-rich preparation, obtained from oat bran by enzymatic hydrolysis, was tested in vitro on $\mathrm{H}_{2} \mathrm{O}_{2}$-stressed dermal human fibroblasts and the results demonstrated that the preparation was effective to reduce oxidative stress-induced cell injury, through an enhanced activity of the enzymes SODs and an inhibition of the malondialdehyde (MDA) levels. Although further exploration about the skin care potential in vivo might be necessary, the oat BP preparation was proposed as functional ingredient in anti-aging skin creams to help preventing damages induced by oxidative stress and UV (Feng et al., 2013).

In recent studies, the wound healing potentialities of a Glycine max (soy) lysate, containing BP with amino acid sequences similar to those of ECM proteins present in the human skin, was explored (Tokudome et al., 2012). These ECM-mimetic peptides produced in soy improved wound healing by increasing dermal ECM synthesis, stimulating reepithelialization, promoting cell adhesion and supporting tissue regeneration (Chien et al., 2013). With the main goal of 
TABLE 1 | Examples of plant and microalgae derived peptides used in cosmetics.

\begin{tabular}{|c|c|c|c|}
\hline Source & Type of bioactive peptide (BP) preparation & Main activities & References \\
\hline \multicolumn{4}{|l|}{ Plants } \\
\hline Avena sativa & Enzymatic hydrolysates & $\begin{array}{l}\text { Reduced the oxidative stress-induced cell injury } \\
\text { in skin fibroblasts }\end{array}$ & Feng et al., 2013 \\
\hline Glycine max & Total lysates & $\begin{array}{l}\text { Improved wound healing by increasing ECM } \\
\text { synthesis in the skin, promoting cell adhesion }\end{array}$ & Chien et al., 2013 \\
\hline Triticum vulgare & Chemical/enzymatic hydrolysates & $\begin{array}{l}\text { Improved skin healing capacity; } \\
\text { anti-inflammation activity by reducing NO, IL-6, } \\
\text { TNF-alpha; PGE-2 }\end{array}$ & Burnett et al., 2018 \\
\hline Solanum tuberosum & Preparations obtained by yeast fermentation & $\begin{array}{l}\text { Stimulated lipid metabolism in human aged } \\
\text { keratinocytes }\end{array}$ & Popa et al., 2006 \\
\hline Nicotiana sylvestris cell cultures & $\begin{array}{l}\text { Chemical/enzymatic hydrolysates of plant cell } \\
\text { wall glycoproteins }\end{array}$ & $\begin{array}{l}\text { Inhibited oxidative damages in skin cells, } \\
\text { induced DNA repair factors (GADD45alfa) and } \\
\text { longevity markers (Sirtuins) }\end{array}$ & Apone et al., 2010 \\
\hline Brassica rapa hairy root cultures & $\begin{array}{l}\text { Chemical/enzymatic hydrolysates of plant cell } \\
\text { wall glycoproteins }\end{array}$ & $\begin{array}{l}\text { Depigmentation activity by down regulation of } \\
\text { MITF expression in epidermis cells }\end{array}$ & Sena et al., 2017 \\
\hline Lotus japonicus cell cultures & $\begin{array}{l}\text { Chemical/enzymatic hydrolysates of plant cell } \\
\text { wall glycoproteins }\end{array}$ & $\begin{array}{l}\text { Anti-aging activity by inducing GDF11 } \\
\text { production and consequent collagen and } \\
\text { periostin restoration in skin fibroblasts }\end{array}$ & Tito et al., 2019 \\
\hline \multicolumn{4}{|l|}{ Microalgae } \\
\hline \multirow[t]{2}{*}{ Chlorella pyrenoidosa } & Isolated peptide fractions (430-1350 Da) & $\begin{array}{l}\text { Inhibited UVB-induced MMP-1 expression in } \\
\text { skin fibroblasts by suppressing AP-1, CYR61 } \\
\text { and MCP production }\end{array}$ & Chen et al., 2011 \\
\hline & & $\begin{array}{l}\text { Reduced UVC-induced cytotoxicity by } \\
\text { modulating Caspase-3, FADD and } \\
\text { ADP-ribose-PARP-1 }\end{array}$ & Shih and Cherng, 2012 \\
\hline Arthrospira platensis (Spirulina) & Enzymatic hydrolysates & $\begin{array}{l}\text { Promoted hydration in skin cells by increasing } \\
\text { AQP3, HAS3, and Filaggrin expression; } \\
\text { counteracted osmotic stress damage by } \\
\text { modulating Smith gene expression }\end{array}$ & De Lucia et al., 2018 \\
\hline
\end{tabular}

increasing the number of applicative outputs, other authors developed a plant-based nanofibrous cellulose acetate scaffold, supporting a layer of soy BP extract (Ahn et al., 2018). The scaffold membranes, combined with the soy BP hydrolysate, successfully mimicked the physiological properties of the native skin and promoted fibroblast proliferation, migration and infiltration in vitro. In vivo, the scaffolds accelerated reepithelialization and epidermal thickening, as well as reduced scar formation and collagen mis-assembly during the wound repair stages. These findings provided a valuable example of how plant-derived BP could be employed in a next generation of regenerative dressings to push the envelope of nanofiber technology in the skin care market.

Protein hydrolysates from Triticum vulgare (wheat) have also been produced and proposed as skin and hair-conditioning ingredients in personal care products (Burnett et al., 2018). The $\mathrm{BP}$ contained in the hydrolysate, obtained by acidic, enzymatic or other chemical digestion procedures, have shown to be very effective in vitro in accelerating skin healing and in reducing the release of several inflammatory mediators, such as nitric oxide (NO), Interleukin 6 (IL-6), Tumor Necrosis Factor (TNF) -alpha, and ProstaGlandin E2 (PGE-2) (Sanguigno et al., 2018). To prevent skin sensitization reaction in allergic subjects due to wheat gluten-derived peptides (Adachi et al., 2012), other authors showed that, when the hydrolysis was carried out at longer times, the wheat BP did not exceed 30 amino acid in length and, in contrast to those with average MWs > $10 \mathrm{KDa}$, they did not elicit any hypersensitivity reactions in sensitized individuals, still keeping their biological activity (Burnett et al., 2018).

A Solanum tuberosum (potato) protein hydro-lysate provided an additional example of how BP, generated by a hydrolytic process, activated response mechanisms in skin cells and could be advantageously applied to skin care Cosmetics. The potato hydrolysate stimulated the lipid metabolism in skin keratinocytes when added to the culture medium (Popa et al., 2006), and induced a stronger increase of the long-chain fatty acidcontaining glucosylceramides in aged keratinocytes than in younger ones (Popa et al., 2010). Moreover, besides the effect on glucosylceramide synthases, it was found that the amount of the neutral phospholipids and the gangliosides was significantly induced by the BP-containing potato hydrolysate, suggesting an activation of the PPARs (peroxisome proliferation activated receptors), that are known to trigger the expression of many lipid biosynthesis genes in keratinocytes (Man et al., 2006).

Similar to plants, plant tissues grown as suspension cultures and obtained through green biotechnological approaches represent an even more valuable source of BP. Besides being free of pathogens, pollutants and agrochemical residues, which could contaminate most of the plant-derived extracts, plant tissue cultures rarely contain toxic compounds or potential allergens (Apone et al., 2017). Moreover, plant cells, grown as suspension cultures, are particularly rich in cell wall proteins, 
whose production is enhanced during the culture formation and the developmental process that occurs when pieces of plant tissue are put in liquid media to form cultures (Apone et al., 2007, 2017). The most abundant proteins present in the cell wall are those belonging to the main classes of hydroxy-proline-rich glycoproteins (HRGPs), proline-rich proteins (PRPs), glycinerich proteins (GRPs), and arabinogalactan proteins (AGPs), with high content of glycine and proline (Ringli et al., 2001), which are also the most abundant amino acids in human collagen. A mixture of BP, together with sugars derived from the hydrolysis of the glycoprotein saccharides, was obtained from the digestion of Nicotiana sylvestris cell wall glycoproteins and extensively investigated in vitro for its activity to inhibit oxidative damages in skin cells, as well as for the capacity to induce DNA repair factors, such as the Growth Arrest and DNA-Damage-inducible protein 45 alpha (GADD45 $\alpha$ ) and the longevity markers, Sirtuins (Apone et al., 2010). In addition, the cell wall derived BP stimulated collagen I and collagen III synthesis in human fibroblasts, and significantly inhibited the metallo-proteinases 1, 3, and 9 production, suggesting promising skin anti-aging properties for the cosmetic market. Even though the role of the sugars in skin care has not been fully clarified, several evidences indicated that the sugar fraction contained in cosmetic preparations had beneficial effects on hydration and had an anti-inflammatory effect on dermal cells (Tolg et al., 2014).

An analogous preparation obtained from Brassica rapa root cultures was studied for its capacity to reduce the accumulation of melanin in skin cells both in vitro and ex vivo, by inhibiting the activity and the expression of the enzyme tyrosinase, main responsible of the melanin synthesis in melanocytes (Sena et al., 2015, 2017). The effect of the BP was that of negatively affecting the melanogenesis signal transduction mechanism, by downregulating MITF expression, a key transcription factor involved in the melanin pathway. The depigmenting activity produced by the preparation was also evaluated on skin explants, confirming a significant reduction of melanin content both in the sub-basal and in the basal epidermis layers (Sena et al., 2017).

In a more recent study a peptide/sugar preparation, obtained from the cell walls of Lotus japonicus cell cultures, was characterized for the presence of proline, hydroxyproline and leucine as the main amino acid components and was proposed as anti-aging ingredient for the skin care, thanks to its capacity to induce the expression and the production of a the cell rejuvenating growth factor GDF11 in vitro and a consequent restoration of some ECM component production level, such as collagens and periostin (Tito et al., 2016, 2019).

The chemistry and biological activities of BP obtained from marine algae have been investigated, although they have not been as well characterized as the peptides from other sources (Fan et al., 2014). A number of BP have also been obtained by hydrolysis of microalgae proteins but few of them have been proposed for skin care applications. Several microalgae species have got high protein content, up to $47 \%$ of the dry weight, compared to the terrestrial plants, and many of them evolved unique protein sequences and structures thanks to their adaptations to more complex habitats, such as those related to extreme conditions (Bimonte et al., 2016; Berthon et al., 2017).
Among the large variety of microalgae species, the genus Chlorella and Arthrospira (commonly known as Spirulina) certainly represent the most established and well known sources of compounds in the skin care market. The freshwater grown unicellular alga Chlorella was already known for the different biological effects on human cells, such as boosting immune functions (Suarez et al., 2010), accelerating dioxin elimination (Morita et al., 1999) and preventing the stressinduced ulcers (Tanaka et al., 1997). Recently it was established that the Chlorella derived peptide (CDP) fraction, with molecular distribution of 430-1350 Da, diminished UVBinduced matrix metalloproteinase-1 (MMP-1) and cysteine-rich 61 (CYR61) gene expression and monocyte chemoattractant protein-1 (MCP-1) production in UV-B irradiated fibroblasts (Chen et al., 2011). Moreover, the authors reported that the UVB-suppressed pro-collagen and TbRII (Transforming growth factor, TGF- $\beta$, receptor) mRNAs were restored by CDP treatment. Moreover, CDP inhibited UVB-induced MMP1 expression in skin fibroblasts by reducing the expression of the activator protein-1 (AP-1), CYR61 and MCP-1 (Chen et al., 2011). Further studies by the same authors revealed also the protective effects of CDP against UVC-induced cytotoxicity through the inhibition of the caspase- 3 activity, and reduced the expression of the phosphorylated Fas associated death domain (FADD) and the poly (ADP-ribose) polymerase-1 (PARP-1) (Shih and Cherng, 2012).

Analogously, the microalga Arthrospira platensis (Spirulina), belonging to the group of blue-green Cyanobacteria, is a consistent source of protein, being approximately $60 \%$ of its entire weight (Shabana et al., 2017). A BP-enriched fraction obtained from Spirulina was originally studied for its pharmacological activity on the angiotensin I-converting enzyme (ACE) and its anti-proliferative effect in lung cancer cells (Lu et al., 2010; Czerwonkaa et al., 2018). More recently, it was studied the skin care related activity of two different protein hydrolysates from Spirulina, an extract obtained by microbial fermentation (SEF) and extract obtained by enzymatic digestion (SED), and compared to a total undigested extract (SE) (De Lucia et al., 2018). SDS-PAGE analysis of the extracts was performed and the C-phycocyanin was used as indicator of the degree of protein hydrolysis and generation of BP. It was demonstrated that the SED extract, containing protein derived BP, was the most effective in promoting skin hydration and in fighting skin osmotic stress damages in vitro, by increasing the gene expression of factors specifically involved in the water balance maintenance in keratinocytes, such as the aquaporin 3 , hyaluronic acid synthase 3 and filaggrin. Moreover, the extract was able to abolish ROS induction caused by oxidative stress agents, and to counteract osmotic stress damage by modulating Smit gene ( $\mathrm{Na}+$ /myoinositol cotransporter), that was responsible for an increased uptake of osmolytes (De Lucia et al., 2018).

\section{Limitations in the Use of Plant and Microalgae-Derived Peptides}

As reported in Table 1, the most used plant and microalgae peptides in Cosmetics are obtained by protein hydrolysis and 
consist of mixtures of peptides of different sizes. Although these hydrolysates may have a broad range of biological activities thanks to their complex nature, their use may be limited in Cosmetics whether a more specific biological function is preferred. The choice of a specific peptide with a known amino acid sequence and length can be sometimes suitable when the interaction with a single and defined target is desired, thus avoiding interactions with other unspecific biological components. This is particularly true in the Pharmaceutical field, where the employment of peptides as drugs is in perfect agreement with the aim of modulating a target-molecule without disturbing other biochemical functions and avoiding undesired side-effects. Analogously, the study of a single peptide activity could be preferred in some cosmetic applications as well, but the isolation of a single peptide fraction from plant and microalgae hydrolysates may become very challenging. Moreover, the most frequently used technologies to isolate peptides from more complex mixtures still include chromatography and pressuredriven filtration processes, which would increase the final cost of the products, making them no longer sustainable for the cosmetic industry (Fan et al., 2014).

An additional limitation could be associated with the risk of potential allergens, since most of the peptide preparations are produced as unpurified mixtures of several components (Jack et al., 2013). Plant and microalgae hydrolysates may contain allergens and potentially toxic contaminating compounds, whose presence must be necessarily certified. Thus, to ensure conformity to the quality standards and answer the safety concerns, the hydrolysates must be subjected to chemical analysis once they are developed as new active ingredients for cosmetic applications. In other case, additional studies on how to prevent and limit the possible allergic reactions due to identified chemicals may even become necessary (Goossens, 2011). For these reasons, in Cosmetics peptide preparations deriving from plant tissue cultures have today become preferable to common plant extracts, because they derive from biological sources grown in the laboratory, under controlled and axenic conditions, where the risk of the presence of potential allergens and environmental pollutants is almost completely abolished.

\section{CONCLUSION AND FUTURE REMARKS}

As described through the reported examples, BP, deriving from plant and microalgae sources, possess a broad spectrum of

\section{REFERENCES}

Adachi, R., Nakamura, R., Sakai, S., Fukutomi, Y., and Teshima, R. (2012). Sensitization to acid-hydrolyzed wheat protein by transdermal administration to BALB/c mice, and comparison with gluten. Allergy 67, 1392-1399. doi: 10. $1111 /$ all.12018

Ahn, S., Chantre, C. O., Gannon, A. R., Lind, J. U., Campbell, P. H., Grevesse, T., et al. (2018). Soy protein/cellulose nanofiber scaffolds mimicking skin extracellular matrix for enhanced wound healing. Adv. Healthcare Mater. 7:e1701175. doi: 10.1002/adhm.201701175

Aldag, C., Teixeira, D. N., and Leventhal, P. S. (2016). Skin rejuvenation using cosmetic products containing growth factors, cytokines, and matrikines: biological activities and their uses as ingredients in skin care and cosmetic products are acquiring more and more opportunities.

Moreover, once derived from plants or microalgae, BP can be used as combinations and mixture with other metabolites in cosmetic formulas, and can exert their biological effects with very low risk of inducing allergenic reaction or undesired side effects.

Despite of the significant progress in the isolation and the characterization of BP from natural sources, as well as the assessment of their biological activities, there are still some aspects, as their production at large scale and the activity maintenance in formulas, which would need further studies in order to extend the range of applications and fulfill the requirements of the continuously growing cosmetic market.

As future development, the plant and microalgae can provide even more innovative opportunities to develop new products for the cosmetic market, thanks to their enormous versatility: for example, new species may represent a valuable source of unexplored BP with novel chemical features and unexpected biological properties. In addition, many plant and microalgae species can be employed as natural biofactories of recombinant protein and peptides with specific sequences and structures, whose production by chemical synthesis may present some limitations. Indeed, thanks to the recent progresses of Molecular Biology, the expression of proteins and peptides in plant and microalgae by using genetic transformation has become a common practice. Although the employment of genetically modified organisms to produce recombinant compounds has been adopted in Medicine for years, in Cosmetics the feedback of the consumers about this topic has not been totally positive so far, probably because of their limited understanding and unfamiliarity about this issue, and certainly the unclearness of the current legislation is not helping either. Nevertheless, proteins and BP produced in plant and microalgae systems can be considered even safer than those produced through conventional methods, thus they have got all the right credentials to be adopted as ingredients in different human health care products.

\section{AUTHOR CONTRIBUTIONS}

All authors conceived and designed the manuscript, and revised, read, and approved the final version of the manuscript.

a review of the literature. Clin. Cosmet. Investig. Dermatol. 9, 411-419. doi: $10.2147 /$ ccid.s116158

Apone, F., Barbulova, A., Zappelli, C., and Colucci, G. (2017). Green Biotechnology in Cosmetics: Using Plant Cell Cultures as Sources of Active Ingredients. Milano MI: Teknoscienze publisher \& event organiser.

Apone, F., Tito, A., Carola, A., Arciello, S., Tortora, A., Filippini, L., et al. (2010). A mixture of peptides and sugars derived from plant cell walls increases plant defense responses to stress and attenuates ageing-associated molecular changes in cultured skin cells. J. Biotechnol. 145, 367-376. doi: 10.1016/j.jbiotec.2009.11.021

Apone, F., Tito, A., Colucci, G., and Chrispeels, M. J. (2007). Method for the Preparation of a Composition Based on 4-hydroxyproline and the Uses There 
of in the Agronomical Field. U.S. Patent No WO2007104489. Naples: Arterra Bioscience srl.

Ariza-Ortega, T. J., Zenón-Briones, E. Y., Castrejón-Flores, J. L., Yanez-Fernandez, J., Gomez-Gomez, M., and Oliver-Salvador, M. C. (2014). Angiotensin-I converting enzyme inhibitory, antimicrobial, and antioxidant effect of bioactive peptides obtained from different varieties of common beans (Phaseolus vulgaris, L.) with in vivo antihypertensive activity in spontaneously hypertensive rats. Eur. Food Res. Technol. 239, 785-794. doi: 10.1007/s00217-0142271-3

Badenhorst, T., Svirskis, D., and Wu, Z. (2014). Pharmaceutical strategies for the topical dermal delivery of peptides/proteins for cosmetic and therapeutic applications. Austin J. Pharmacol. Ther. 2, 6-10.

Barba, C., Méndez, S., Roddick-Lanzilotta, A., Kelly, R., Parra, J. L., and Coderch, L. (2008). Cosmetic effectiveness of topically applied hydrolysed keratin peptides and lipids derived from wool. Skin Res. Technol. 14, 243-248. doi: 10.1111/j. 1600-0846.2007.00280.x

Berthon, J. Y., Nachat-Kappes, R., Bey, M., Cadoret, J. P., Renimel, I., and Filaire, E. (2017). Marine algae as attractive sourse to skin care. Free Rad. Res. 51, 555-567. doi: $10.1080 / 10715762.2017 .1355550$

Bhat, Z. F., Kumar, S., and Bhat, H. F. (2015). Bioactive peptides from egg: a review. Nutr. Food Sci. 45, 190-212. doi: 10.1108/nfs-10-2014-0088

Bimonte, M., De Lucia, A., Carola, A., Tito, A., Buono, S., Langellotti, A. L., et al. (2016). Galdieria sulphuraria relieves oily and seborrheic skin by inhibiting the $5 \alpha$-Reductase expression in skin cells and reducing sebum production in vivo. Trichol. Cosmetol. Open J. 1, 11-18.

Blanes-Mira, C., Clemente, J., Jodas, G., Gil, A., Fernández-Ballester, G., Ponsati, B., et al. (2002). A synthetic hexapeptide (Argireline) with antiwrinkle activity. Int. J. Cosmet. Sci. 24, 303-310. doi: 10.1046/j.1467-2494.2002.00153.x

Burnett, C. L., Bergfeld, W. F., Belsito, D. V., Hill, A. R., Klaassen, C. D., Liebler, D. C., et al. (2018). Safety assessment of hydrolyzed wheat protein and hydrolyzed wheat gluten as used in Cosmetics. Intern. J. Toxicol. 37, 55S-66S. doi: $10.1177 / 1091581818776013$

Carrasco-Castilla, J., Hernández-Álvarez, A. J., Jiménez-Martínez, C., GutiérrezLópez, G. F., and Dávila-Ortiz, G. (2012). Use of proteomics and peptid-omics methods in food bioactive peptide science and engineering. Food Eng. Rev. 4, 224-243. doi: 10.1007/s12393-012-9058-8

Chen, C. L., Liou, S. F., Chen, S. J., and Shih, M. F. (2011). Protective effects of chlorella-derived peptide on UVB-induced production of MMP-1 and degradation of procollagen genes in human skin fibroblasts. Regul. Toxicol. Pharmacol. 60, 112-119. doi: 10.1016/j.yrtph.2011.03.001

Chien, K. B., Makridakis, E., and Shah, R. N. (2013). Three-dimensional printing of soy protein scaffolds for tissue regeneration. Tissue Eng. Part C Methods 19, 417-426. doi: 10.1089/ten.tec.2012.0383

Czerwonkaa, A., Kaławaja, K., Sławińska-Brychb, A., Lemieszekc, M. K., Bartnikd, M., Wojtanowskid, K. K., et al. (2018). Anticancer effect of the water extract of a commercial Spirulina (Arthrospira platensis) product on the human lung cancer A549 cell line. Biomed. Pharmacother. 106, 292-302. doi: 10.1016/j.biopha.2018. 06.116

Dae, D. H., Jung, D. H., Kim, S. J., and Park, K. M. (2014). Galloyl-RGD as a new cosmetic ingredient. BMC Biochem. 15:18. doi: 10.1186/1471-2091-15-18

De Lucia, A., Zappelli, C., Angelillo, M., Langelotti, A. L., Fogliano, V., Cucchiara, M., et al. (2018). A Novel Biotechnological Active Ingredient, Derived From the Microalga Spirulina, Increases Hydration and Reduces Osmotic Stress in Skin Cells. Milano MI: Teknoscienze publisher \& event organiser.

D’Hondt, M., Bracke, N., Taevernier, L., Bert, G., Verbeke, F., Wynendaele, E., et al. (2014). Related impurities in peptide medicines. J. Pharm. Biomed. Anal. 101, 2-30. doi: 10.1016/j.jpba.2014.06.012

Fan, X., Bai, L., Zhu, L., Yang, L., and Zhang, X. (2014). Marine algae-derived bioactive peptides for human nutrition and health. J. Agric. Food Chem. 62, 9211-9222. doi: 10.1021/jf502420h

Farwick, M., Grether-Bec, S., Marini, A., Maczkiewitz, U., Lange, J., Köhler, T., et al. (2011). Bioactive tetrapeptide GEKG boosts extracellular matrix formation: in vitro and in vivo molecular and clinical proof. Exp. Dermatol. 20, 602-604. doi: 10.1111/j.1600-0625.2011.01307.x

Feng, B., Ma, L., Yao, J., Fang, Y., Mei, Y., and Wei, S. (2013). Protective effect of oat bran extracts on human dermal fibroblast injury induced by hydrogen peroxide. J. Zhejiang Univ. Sci. B Biomed. Biotechnol. 14, 97-105. doi: 10.1631/ jzus.B1200159
Goossens, A. (2011). Contact allergic reactions to cosmetics. J. Allergy 2011:467071. doi: 10.1155/2011/467071

Guzman, F., Barberis, S., and Illaness, A. (2007). Peptide synthesis: chemical or enzymatic. Electron. J. Biotechnol. 10:2.

Haque, E., Chand, R., and Kapila, S. (2008). Biofunctional properties of bioactive peptides of milk origin. Food Rev. Intern. 25, 28-43. doi: 10.1080/ 87559120802458198

Hartmann, R., and Meisel, H. (2007). Food-derived peptides with biological activity: from research to food applications. Curr. Opin. Biotech. 18, 163-169. doi: 10.1016/j.copbio.2007.01.013

Ito, Y., Nakanomyo, I., Motose, H., Iwamoto, K., Sawa, S., Dohmae, N., et al. (2006). Dodeca-CLE as peptides as suppressors of plant stem cell differentiation. Science 313, 842-845. doi: $10.1126 /$ science. 1128436

Jack, A. R., Norris, P. L., and Storrs, F. J. (2013). Allergic contact dermatitis to plant extracts in cosmetics. Semin. Cutan. Med. Surg. 32, 140-146. doi: 10.12788/j. sder.0019

Lemes, A. C., Sala, L., Ores, J. D. C., Braga, A. R. C., Egea, M. B., and Fernandes, K. F. (2016). A review of the latest advances in encrypted bioactive peptides from protein-rich waste. Int. J. Mol. Sci. 17:950. doi: 10.3390/ijms17060950

Lu, J., Ren, D. F., Xue, Y. L., Sawano, Y., Miyakawa, T., and Tanokura, M. (2010). Isolation of an antihypertensive peptide from alcalase digest of Spirulina platensis. J. Agric. Food Chem. 23, 7166-7171. doi: 10.1021/jf100193f

Maczkiewitz, U., Ulrich, P., Maus, L., and Schrader, A. (2018). "Triggering of Collagen, Fibronectin and Elastin in human skin by topical application of the novel biomimetic tetrapeptide," in Proceedings of the Abstract of 30th IFSCC Congress, Munich.

Maestri, E., Marmiroli, M., and Marmiroli, N. (2016). Bioactive peptides in plantderived foodstuffs. J. Proteo. 16, 140-155. doi: 10.1016/j.jprot.2016.03.048

Man, M. Q., Choi, E. H., Schmuth, M., Crumrine, D., Uchida, Y. Elias, P. M., et al. (2006). Basis for improved permeability barrier homeostasis induced by PPAR and LXR activators: liposensors stimulate lipid synthesis, lamellar body secretion, and post- secretory lipid processing. J. Invest. Dermatol. 126, 386-392. doi: 10.1038/sj.jid.570 0046

Moldes, A. B., Vecino, X., and Cruz, J. M. (2017). "Nutraceuticals and food additives," in Curr Develop Biotech Bioengineer: Food and Beverages Industry, eds A. Pandey, G. Du, M. A. Sanroman, C. R. Soccol, and C.-G. Dussap (Amsterdam: Elsevier), 143-164. doi: 10.1016/b978-0-444-63666-9.00006-6

Moller, N. P., Scholz-Ahrens, K. E., Roos, N., and Schrezenmeir, J. (2008). Bioactive peptides and proteins from foods: indication for health effects. Eur. J. Nutr. 47, 171-182. doi: 10.1007/s00394-008-0710-2

Morita, K., Matsueda, T., Iida, T., and Hasegawa, T. (1999). Chlorella accelerates dioxinexcretion in rats. J. Nutr. 129, 1731-1736. doi: 10.1093/jn/129.9.1731

Pickart, L., and Schagen, S. (2015). New data of the Cosmeceutical and tripeptide GHK. Sofw. J. 9:141.

Popa, I., Abdul-Malak, N., and Portoukalian, J. (2010). The weak rate of sphingolipid biosynthesis shown by basal keratinocytes isolated from aged vs. young donors is fully rejuvenated after treatment with peptides of a potato hydrolysate. Int. J. Cosmet. Sci. 32, 225-232. doi: 10.1111/j.1468-2494.2009. 00571.x

Popa, I., Bennaceur, K., Abdul-Malak, N., Perrier, E., Schmitt, D., and Portoukalian, J. (2006). Studies of compounds that enhance sphingolipid metabolism in human keratinocytes. Int. J. Cosmet. Sci. 28, 53-59. doi: 10.1111/j.1467-2494. 2006.00298.x

Proksch, E., Schunck, M., Zague, V., Segger, D., Degwert, J., and Oesser, S. (2014). Oral intake of specific bioactive collagen peptides reduces skin wrinkles and increases dermal matrix synthesis. Skin Pharmacol. Physiol. 27, 113-119. doi: $10.1159 / 000355523$

Rigano, L. (2017). Halal Regulations: Where Culture and Cosmetics Meet. Northbrook, IL: Cosmetics \& Toiletries.

Ringli, C., Keller, B., and Ryser, U. (2001). Glycine-rich proteins as structural components of plant cell walls. Cell Mol. Life Sci. 58, 1430-1441. doi: 10.1007/ pl00000786

Salas, C. E., Badillo-Corona, J. A., Ramírez-Sotelo, G., and Oliver-Salvador, C. (2015). Biologically active and antimicrobial peptides from plants. BioMed. Res. Intern. 2015:102129. doi: 10.1155/2015/102129

Sánchez, A., and Vázquez, A. (2017). Bioactive peptides: a review. Food Q. Saf. 1, $29-46$. 
Sanguigno, L., Casamassa, A., Funel, N., Minale, M., Riccio, R., Riccio, S., et al. (2018). Triticum vulgare extract exerts an anti- inflammatory action in two in vitro models of inflammation in microglial cells. PLoS One 13:e197493. doi: 10.1371/journal.pone.0197493

Schaller, A. (2001). Bioactive peptides as signal molecules in plant defense, growth and development. Stud. Nat. Prod. Chem. 25, 367-411. doi: 10.1016/s15725995(01)80012-0

Sena, L. M., Tito, A., Bimonte, M., Barbulova, A., Apone, F., and Colucci, G. (2015). Cosmetic Compositions Based on Extracts Derived From Brassica rapa, var. pekinensis Hairy Root Cultures (HRC) to Treat Skin Pigmentation. U.S. Patent No MI2015A 000315. Naples: Vitalab srl.

Sena, L. M., Zappelli, C., Apone, F., Barbulova, A., Tito, A., Leone, A., et al. (2017). Brassica rapa hairy root extracts promote skin depigmentation by modulating melanin production and distribution. J. Cosmet. Dermatol. 17, 246-257. doi: 10.1111 /jocd. 12368

Shabana, E. F., Gabr, M. A., Moussa, H. R., El-Shaer, E. A., and Ismaiel, M. M. S. (2017). Biochemical composition and antioxidant activities of Arthrospira (Spirulina) platensis in response to gamma irradiation. Food Chem. 214, 550-555. doi: 10.1016/j.foodchem.2016.07.109

Shih, M. F., and Cherng, J. Y. (2012). Protective effects of Chlorella-derived peptide against UVC-induced cytotoxicity through inhibition of caspase-3 activity and reduction of the expression of phosphorylated FADD and cleaved PARP-1 in skin fibroblasts. Molecules 17, 9116-9128. doi: 10.3390/molecules 170 89116

Suarez, E. R., Kralovec, J. A., and Grindley, T. B. (2010). Isolation of phosphorylated polysaccharides from algae: the immunostimulatory principle of Chlorella pyrenoidosa. Carbohydr. Res. 345, 1190-1204. doi: 10.1016/j.carres. 2010.04.004

Suarez, M., Haenni, M., Canarelli, S., Fisch, F., Chodanowski, P., Servis, C., et al. (2005). Structure-function characterization and optimization of a plant-derived antibacterial peptide. Antimicrob. Agents Chemoter. 49, 3847-3857. doi: 10. 1128/aac.49.9.3847-3857.2005

Tanaka, K., Yamada, A., Nada, K., Shoyama, Y., Kubo, C., and Nomoto, K. (1997). Oral administration of a unicellular green algae, Chlorella vulgaris, prevents stress induced ulcer. Planta Med. 63, 465-466. doi: 10.1055/s-2006-957736

Tito, A., Barbulova, A., Bimonte, M., Apone, F., and Colucci, G. (2016). Cosmetic Use of Extracts Derived From Somatic Embryo Enriched Plant Cell Cultures and Cosmetic Compositions Containing those Extracts. U.S. Patent No WO2016173867. Naples: Vitalab srl.

Tito, A., Barbulova, A., Zappelli, C., Leone, M., Ruvo, M., Mercurio, F. A., et al. (2019). The growth differentiation factor 11 is involved in skin fibroblast ageing and is induced by a preparation of peptides and sugars derived from plant cell cultures. Mol. Biotechnol. 61, 209-220. doi: 10.1007/s12033-019-00154-w

Tokudome, Y., Nakamura, K., Kage, M., Todo, H., Sugibayashi, K., and Hashimoto, F. (2012). Effects of soybean peptide and collagen peptide on collagen synthesis in normal human dermal fibroblasts. Int. J. Food Sci. Nutr. 63:689. doi: 10.3109/ 09637486.2011 .652597

Tolg, C., Telmer, P., and Turley, E. (2014). Specific sizes of hyaluronan oligosaccharides stimulate fibroblast migration and excisional wound repair. PLoS One 9:e88479. doi: 10.1371/journal.pone.0088479

Tsai, W. C., Hsu, C. C., Chung, C. Y., Lin, M. S., Li, S. L., and Pang, J. H. (2007). The pentapeptide KTTKS promoting the expressions of type I collagen and transforming growth factor-beta of tendon cells. J. Orthop. Res. 25, 1629-1634. doi: 10.1002/jor.20455

Watson, R. E., Ogden, S., Cotterell, L. F., Bowden, J. J., Bastrilles, J. Y., Long, S. P., et al. (2009). A cosmetic 'anti-ageing' product improves photoaged skin: a double-blind, randomized controlled trial. Br. J. Dermatol. 161, 419-426. doi: 10.1111/j.1365-2133.2009.09216.x

Yokoyama, T., and Mohri, S. (2008). Prion diseases and emerging prion diseases. Curr. Med. Chem. 15, 912-916. doi: 10.2174/092986708783955437

Conflict of Interest Statement: $\mathrm{AB}$ was employed by the company Arterra Bioscience srl.

The remaining authors declare that the research was conducted in the absence of any commercial or financial relationships that could be construed as a potential conflict of interest.

Copyright (C) 2019 Apone, Barbulova and Colucci. This is an open-access article distributed under the terms of the Creative Commons Attribution License (CC BY). The use, distribution or reproduction in other forums is permitted, provided the original author(s) and the copyright owner(s) are credited and that the original publication in this journal is cited, in accordance with accepted academic practice. No use, distribution or reproduction is permitted which does not comply with these terms. 